\title{
Poly(vinyl alcohol) with High Diad-Syndiotacticity and High Melting Point
}

\author{
Ryohei Fukae, Tohei Yamamoto, ${ }^{*}$ Yasuhiro Fujita, ${ }^{*}$ Nobuhiro Kawatsuki, ${ }^{*}$ \\ Osamu SANGEN, ${ }^{*}$ and Mikiharu KAMACHI** \\ Himeji Junior College, Shinzaikehoncho, Himeji 670, Japan \\ * Faculty of Engineering, Himeji Institute of Technology, Shosha, Himeji 671-22, Japan \\ ** Faculty of Science, Osaka University, Machikaneyama, Toyonaka 560, Japan
}

(Received September 24, 1996)

KEY WORDS Poly(vinyl alcohol) / High Syndiotacticity / Vinyl Pivalate / Crystal Melting / Dynamic Viscoelasticity /

Physical properties and new industrial applications of poly(vinyl alcohol) (PVA) with high syndiotacticity have become of interest in recent years.

PVA with diad-syndiotacticity of $63 \%$ was prepared from an initiator-free photo-emulsion polymerization of vinyl pivalate (VP) followed by saponification of the resulting poly(vinyl pivalate) (PVP) ${ }^{1}$ and its characteristics were much different from those of the usual one. ${ }^{2}$ During the course of study, radical polymerization of VP in various solvents was examined and non polar solvents were favorable for syndiotactic propagation. ${ }^{3}$ Lower temperatures give rise to higher syndiotacticity in radical polymerization of vinyl esters, ${ }^{4}$ and even a slight difference in tacticity of PVA substantially affects physical properties.

In the present work, to get PVA of higher syndiotacticity, radical polymerization of $\mathrm{VP}$ at $-40^{\circ} \mathrm{C}$ using $n$-hexane as a solvent was tried, and PVA with diad-syndiotacticity of $69 \%$ was obtained via saponification of PVP.

Although many investigations regarding PVA having high syndiotacticity have been reported, most were carried out using PVA derived from poly(vinyl trifluoroacetate). The preparation of PVA with syndiotacticity of $64 \%$, given by radical polymerization of vinyl trifluoroacetate (VTFAc) at $-40^{\circ} \mathrm{C}$ in $n$-hexane, was reported. ${ }^{5}$ As for PVA having the highest syndiotacticity in radical polymerization, syndiotacticity of $67 \%$ has been shown by Yamaura et al. This was based on the radical polymerization of VTFAc at $-20^{\circ} \mathrm{C}$ in toluene and quoted as a reference. No detailed information concerning physical properties can be given.

PVA having the highest syndiotacticity ( $\mathrm{ca} .74 \%$ ), derived from poly(vinyl trimethylsilyl ether) by cationic polymerization process, has been reported. ${ }^{6}$ However, there is no description of physical properties.

\section{EXPERIMENTAL}

\section{Preparation of $P V A$}

Fifty milliliters $(0.34 \mathrm{~mol})$ of VP, $200 \mathrm{ml}$ of $n$-hexane and $17.3 \mathrm{mg}(0.11 \mathrm{mmol})$ of $\alpha, \alpha^{\prime}$-azobisisobutyronitrile were placed in a Pyrex Kjeldahl flask. After degassing the mixture, the flask was sealed under vacuum and the mixture was irradiated with a high pressure mercury lamp for 10 days. The mixture was poured into a mixture of methanol and water $(4: 1, \mathrm{v} / \mathrm{v})$, and the precipitated PVP was collected by filtration and dried in vacuo at $60^{\circ} \mathrm{C}$. Polymerization of VP gave PVP in $70 \%$ conversion.

PVP was saponified to give PVA as previously reported. ${ }^{7}$ PVA was filtered, washed with methanol and dried in vacuo at $60^{\circ} \mathrm{C}$.

\section{Measurement}

The ${ }^{1} \mathrm{H}$ NMR spectrum was recorded on a JEOL JNM EX270 at $60^{\circ} \mathrm{C}$ using dimethyl sulfoxide (DMSO)$d_{6}$ as a solvent. Tacticity of PVA was determined by evaluating triplet spectrum of hydroxyl proton in a tactic structure. ${ }^{8}$ Resonances are ascribed to triad-syndiotactic $(4.11 \mathrm{ppm})$, heterotactic $(4.35 \mathrm{ppm})$, and isotactic $(4.52$ ppm) sequences. Tactic contents were calculated from relative ratios of integrated values of split peaks. Triadtacticity was converted to diad-tacticity based on the tactic contents obtained. Average degrees of polymerization $\left(P_{n}\right)$ of PVAs were determined from the intrinsic viscosity of acetylated PVA in benzene at $30^{\circ} \mathrm{C}$.

Crystallinities of film samples were estimated from density on the basis of the assumption that the density of a fully amorphous sample and fully crystalline sample of PVA is 1.269 and $1.345 \mathrm{~g} \mathrm{~cm}^{-3}$ respectively. ${ }^{9}$ Density was measured by the floating method in light paraffin liquid-carbon tetrachloride mixed solution at $25^{\circ} \mathrm{C}$.

Determination of the melting point was carried out using a Seiko SSC5200 differential scanning calorimeter. The heating rate was $10^{\circ} \mathrm{C} \mathrm{min}^{-1} . \Delta H_{\mathrm{u}}\left(\mathrm{kJ} \mathrm{mol}^{-1}\right)$ of the sample was obtained by dividing the value of heat of fusion by the degree of crystallinity.

Dynamic viscoelastic analysis was performed with film samples on a Rheology Engineering Dynamic Viscoelastic Analyzer DVE-V4 instrument at $110 \mathrm{~Hz}$ in the temperature range from $-130^{\circ} \mathrm{C}$ to $250^{\circ} \mathrm{C}$ at a heating rate of $2^{\circ} \mathrm{C} \mathrm{min}-1$

Solubility tests of PVAs were carried out, adding $10 \mathrm{mg}$ each sample to $10 \mathrm{ml}$ of solvent kept at fixed temperature.

PVA film was prepared from DMSO solution by casting. Annealing of the film sample was carried out at fixed temperatures under inert atmosphere for $30 \mathrm{~min}$.

\section{RESULTS AND DISCUSSION}

Tacticity of PVA obtained by the procedure mention- 
Table I. Abbreviations and physical properties of PVAs

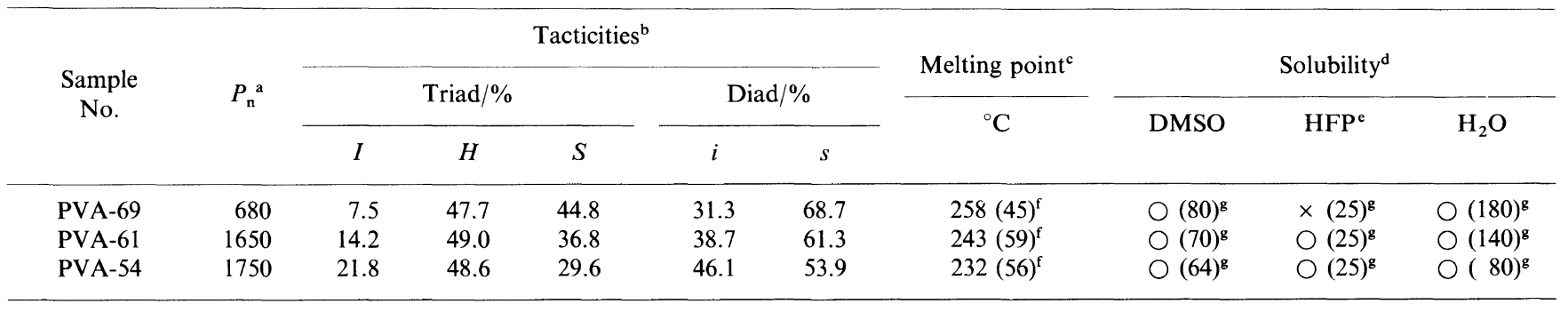

${ }^{\text {a }}$ Average degree of polymerization. ${ }^{\mathrm{b}}$ Determined from ${ }^{1} \mathrm{H}$ NMR spectrum; $I$, triad-isotacticity; $H$, -heterotacticity; $S$, -syndiotacticity; $i$, diadisotacticity; $s$, -syndiotacticity. ${ }^{\mathrm{c}}$ Melting point determined by DSC. Annealed sample at $200^{\circ} \mathrm{C}$ for $30 \mathrm{~min}$ was used. ${ }^{\mathrm{d}} 10 \mathrm{mg}$ of PVA dissolved in $10 \mathrm{ml}$ of each solvent: $\bigcirc$, soluble; $\times$, insoluble. ${ }^{\mathrm{e}} 1,1,1,3,3,3$-Hexafluoro-2-propanol. ${ }^{\mathrm{f}}$ Degree of crystallinity $(\%) .{ }^{\mathrm{g}}(\mathrm{)})$, temperature dissolved $\left({ }^{\circ} \mathrm{C}\right)$.

ed in the experimental section is listed in Table I. The diad-syndiotacticity is $c a$. $69 \%$, the highest in radical polymerization hitherto reported. PVA having syndiotacticity of $69 \%$ is abbreviated hereafter as PVA-69. In Table I, PVA-61 is derived from PVP polymerized in methanol solution at $60^{\circ} \mathrm{C}$, and PVA-54 is a commercial PVA from poly(vinyl acetate).

Solubility tests as shown in Table I indicate that although 1,1,1,3,3,3-hexafluoro-2-propanol is a good solvent for PVA-61 and PVA-54, it is not a good solvent for PVA-69. PVA-69 is soluble in DMSO at $80^{\circ} \mathrm{C}$ and in $\mathrm{H}_{2} \mathrm{O}$ at $180-190^{\circ} \mathrm{C}$ in a sealed tube.

\section{Crystallinity and Melting Point of PVA-69}

DSC thermograms of PVA samples annealed at $200^{\circ} \mathrm{C}$ for $30 \mathrm{~min}$ are shown in Figure 1. Melting points of the three samples are $232^{\circ} \mathrm{C}$ for PVA-54, $243^{\circ} \mathrm{C}$ for PVA-61 and $258^{\circ} \mathrm{C}$ for PVA-69, respectively. This indicates that the melting point becomes higher with syndiotacticity. The melting point of PVA-69 is extremely high. $\Delta H_{\mathrm{u}}$ in Figure 1 are $6.9 \mathrm{~kJ} \mathrm{~mol}^{-1}$ for PVA-54, $7.1 \mathrm{~kJ} \mathrm{~mol}^{-1}$ for PVA-61, and $7.5 \mathrm{~kJ} \mathrm{~mol}^{-1}$ for PVA-69. The apparent cohesive energy force of PVA-69 is higher than those of PVA-54 and PVA-61, and the extent of thickening of crystallites in PVA-69 may be higher than in PVA-54 and PVA-61.

The degrees of crystallinity of PVA-54, PVA-61, and PVA-69 films after being annealed at $180^{\circ} \mathrm{C}$ for $30 \mathrm{~min}$ were $55 \%, 54 \%$, and $30 \%$, respectively. When the films were annealed at $200^{\circ} \mathrm{C}$, those of PVA-54, PVA-61 and PVA-69 were $56 \%, 59 \%$, and $45 \%$. The lowest crystallinity of PVA-69 under these conditions is attributable to stronger intermolecular force, which makes segment mobility more difficult and should restrict molecular orientation at lower temperatures. When PVA-69 film was annealed at $240^{\circ} \mathrm{C}$, crystallinity of $60 \%$ was attained.

\section{Dynamic Viscoelasiticity of PVA-69}

Figure 2 shows dynamic viscoelastic behavior of PVA films annealed at $180^{\circ} \mathrm{C}$ for $30 \mathrm{~min}$. A characteristic change of dynamic storage modulus $\left(E^{\prime}\right)$ at crystal relaxation region above $140^{\circ} \mathrm{C}$ was observed. In the case of undrawn cast films of PVA with syndiotacticity in the range below $63-64 \%$, for the most part, $E^{\prime}$ rapidly decreased when temperatures rose to the crystal relaxation region. ${ }^{10}$ However, changes in $E^{\prime}$ of PVA-69 in the temperature range above $190^{\circ} \mathrm{C}$ are extremely small and $E^{\prime}$ are almost constant $\left(3-4 \times 10^{8} \mathrm{~Pa}\right)$ in the range of $190^{\circ} \mathrm{C}$ to $250^{\circ} \mathrm{C}$. This is unusual for undrawn and annealed films of PVA

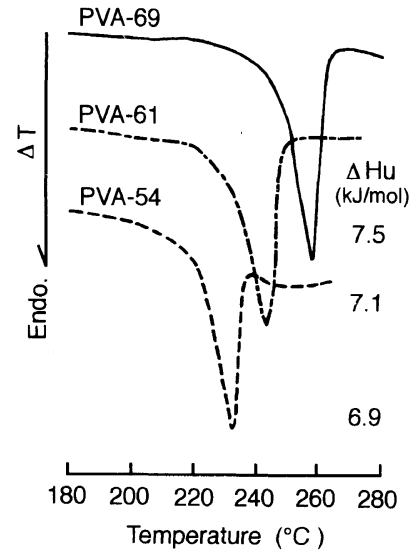

Figure 1. Heating thermograms of PVAs: Heating rate $10^{\circ} \mathrm{Cmin}^{-1}$; $\Delta H_{\mathrm{u}}\left(\mathrm{kJ} \mathrm{mol}^{-1}\right)$, heat of fusion divided by degree of crystallinity.

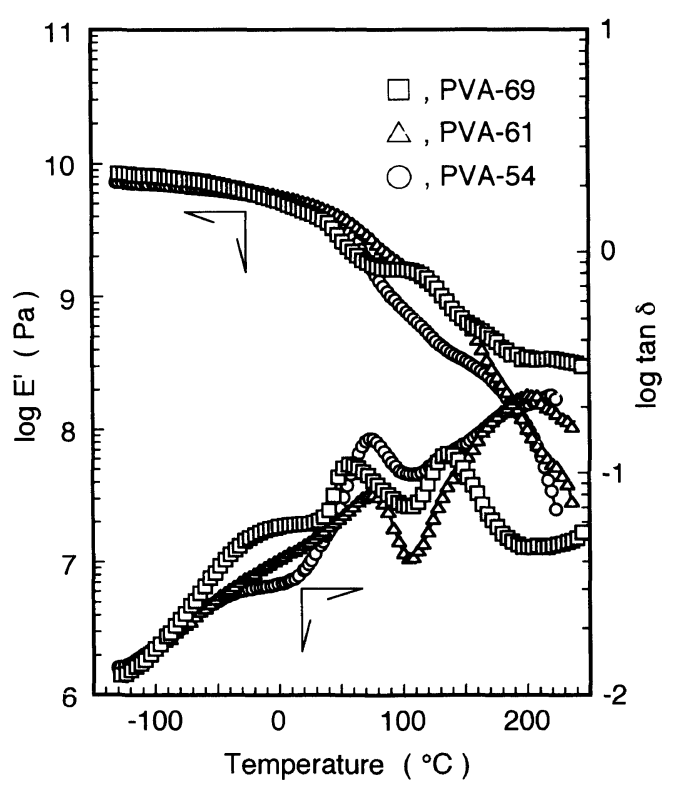

Figure 2. Temperature dependence of dynamic storage modulus $E^{\prime}$ and $\tan \delta$ for PVA films: Frequency, $110 \mathrm{~Hz}$; heating rate, $2^{\circ} \mathrm{Cmin}^{-1}$.

examined so far by us.

Two dispersion peaks can be separately observed on the $\tan \delta$ curve for PVA-69 as shown in Figure 2. One in the low temperature region is due to $\alpha_{\mathrm{a}}$ relaxation, i.e., based on the micro-Brownian motion of the polymer chain in the amorphous region, and another is possibly due to $\beta_{\mathrm{c}}$ relaxation resulted from the local mode of molecular chains in the crystal region. Local movement in crystals is caused by lowering of intermolecular force 
with rising temperature.

Nagai and Takayanagi showed $\beta_{\mathrm{c}}$ relaxation of PVA is caused by thermal expansion of a crystal lattice with a rise in temperature, based on determination of apparent activation energy of relaxation in both crystalline and amorphous regions by viscoelastic measurement. ${ }^{11}$ Shiragashi et al. showed, using X-ray analysis, that the relaxation of PVA in the range of $140^{\circ} \mathrm{C}$ can be assigned to mild secondary transition of the crystal phase caused by local molecular motion. ${ }^{12}$

The line plotted of $E^{\prime}$ shows a plateau above the glass transition region ( $\alpha_{\mathrm{a}}$ relaxation region). This seems due to the secondary cross-linked effects of crystallites. The cross-linked effect by crystallites is appreciable in the case of PVA-69 containing more stereoregulated $\mathrm{OH}$ side groups.

As temperature rises, in the crystal relaxation region, such crystallites are regulated and thickened to reach crystal completion. Another dispersion peak on the $\tan \delta$ curve in the high temperature region may be attributed to this mode. Nagai et al. explained that crystalline state and microstructures of PVA remarkably affect the crystal relaxation of dynamic viscoelasticity.

The essentially prominent crystallizability of highly syndiotactic PVA appears to have a low intensity of damping and high $E^{\prime}$ of PVA- 69 above $200^{\circ} \mathrm{C}$. The high melting point of $258^{\circ} \mathrm{C}$ described above for PVA- 69 cor- responds to the crystallizability in the high temperature region. Further consideration should be given to the effects of the degree of polymerization of PVA on viscoelastic behavior.

\section{REFERENCES}

1. T. Yamamoto, S. Yoda, O. Sangen, R. Fukae, and M. Kamachi, Polym. J., 21, 1053 (1989).

2. R. Fukae, T. Yamamoto, O. Sangen, T. Saso, T. Kako, and M. Kamachi, Polym. J., 22, 636 (1990).

3. R. Fukae, K. Kawakami, T. Yamamoto, O. Sangen, T. Kako, and M. Kamachi, Polym. J., 27, 1257 (1995).

4. J. W. L. Fordham, J. Polym. Sci., 39, 321 (1959).

5. K. Yamaura and S. Matsuzawa, "Poly(vinyl alcohol)," Kobunshi Kankokai, Kyoto, 1991, p 30.

6. M. Sumi, S. Nozakura, and S. Murahashi, Kobunshi Kagaku, 24, 424 (1967).

7. T. Yamamoto, S. Yoda, H. Takase, T. Saso, O. Sangen, R. Fukae, M. Kamachi, and T. Sato, Polym. J., 23, 185 (1991).

8. T. Moritani, I. Kuruma, K. Shibatani, and Y. Fujiwara, Macromolecules, 5, 577 (1972)

9. I. Sakurada, T. Nukushina, and Y. Sone, Kobunshi Kagaku, 12 506 (1955).

10. R. Fukae, T. Yamamoto, Y. Imori, R. Hama, T. Yamamoto, and O. Sangen, Polym. Prepr., Jpn., 40, 2896 (1991)

11. A. Nagai and M. Takayanagi, Kogyo Kagaku Zasshi, 68, 836 (1965).

12. K. Shiragashi, K. Ishikawa, and K. Miyasaka, Kobunshi Kagaku, 21, 588 (1964). 